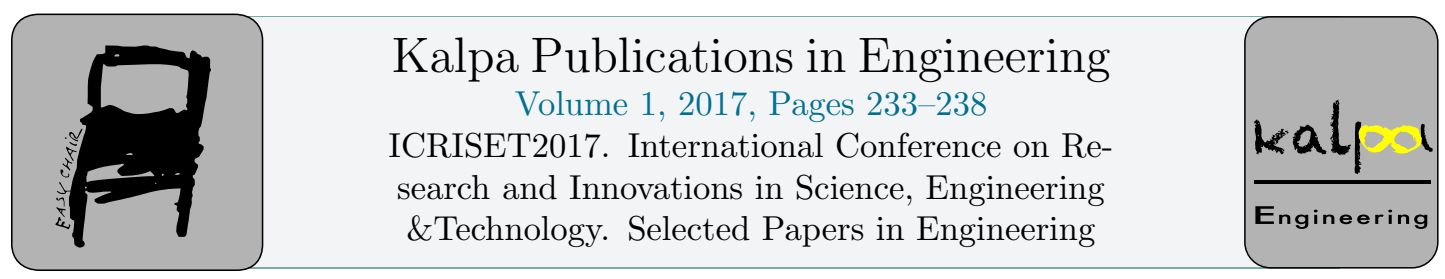

\title{
Analysis of Mechanical Properties of Natural Fiber Composite Beam
}

\author{
Jay H. Khatri ${ }^{1}$, Dr Haresh P. Patolia ${ }^{2}$ and Mr. Ketul B. Brahmbhatt \\ ${ }^{1}$ Research Scholar, ${ }^{2}$ Associated Professor, ${ }^{3}$ Assistant Professor \\ 1,2, ${ }^{3}$ Mechanical Engineering Department, BVM Engineering College, V V Nagar, Anand, India \\ ${ }^{1}$ jayhkhatri@gmail.com, ${ }^{2 h p p a t o l i a @ b v m e n g i n e e r i n g . a c . i n, ~}$ \\ ${ }^{3} \mathrm{kbrahmbhatt@bvmengineering}$. ac .in
}

\begin{abstract}
Natural fiber composite materials are gradually becoming more popular due to light weight, low cost, bio degradability, easy to manufacture, lower environmental impact and less energy requirement for manufacturing. These properties of natural fiber make it suitable for automobile, aerospace and other industrial applications. In present study, analysis of mechanical properties like tensile strength, flexural strength, impact strength and Young's modulus are carried out for various composites. Free vibration characteristics of natural fiber composite beams are also studied analysed. In addition to analytical study, finite element analysis also carried out using ANSYS. In this, the test specimens were modelled in accordance to experimental test specimen and model analysis is performed.
\end{abstract}

Key words: natural fiber, composite material, properties of composite, Finite Element Analysis.

\section{Introduction}

Natural fiber composites are attracting the researcher because of advantages that these fibers make available over conventional reinforcing synthetic fiber. Natural fibers possess properties like light weight, low environmental impact, biodegradability and non-abrasive characteristics. In fact, certain drawbacks such as poor moisture resistance, lower stability, hydrophilic nature, lower life cycle and poor fire resistance properties create the resistance in the use of natural fiber composite. However now a days new surface treatments are developed which are used to increase the mechanical properties of natural fibers makes them available for certain industrial applications. Furqan Ahmad et al [1] reviewed on selection of natural fiber in light of mechanical and economic properties. Fibers are available from different species and various origins. As natural fibers are not free from defects various treatments are suggested. Mechanical properties of various fibers are compared with synthetic fibers. Since glass fiber has occupied mare than $90 \%$ of market for reinforcement in composite industry, lower mechanical properties and poor bonding characteristics of fiber with matrix material limited the use of natural fiber. 
With the development of improved technology mechanical properties of natural fiber are started improving. Despite that natural fibers are currently facing the problem of poor fire resistance, lack of dimensional stability and hydrophilic nature, which tends to affect the mechanical properties.

Begum K. et al [2] presented a brief overview of improvement of mechanical properties of the natural fiber reinforced composite comparing with pure material. To achieve comparative properties like synthetic fibers, more fiber percentage is required. With the increase volume fraction mechanical properties are gradually improved, after certain limit of fiber content depending upon method of processing and adhesion between fiber and resin matrix, it shows decrease in mechanical properties. Since high water absorption weaken the bond between resin and fiber, it tends to reduce the mechanical properties, surface treatments are necessary to reduce water absorption ability of fiber.

S.V. Joshi et al [3] investigated and compared the life cycle of natural fiber composite with synthetic fiber. Life cycle assessment involves study of environmental aspects and potential impact throughout a products life cycle form raw material, production, use and end management option like recycling and disposal. Despite of having lower life cycle natural fiber composites are likely to be superior than glass fiber in many application due to lower environmental impact and requires larger fraction of fiber which reduce the weight of resin matrix and ultimately the weight of component result in less fuel consumption un automobile which increase fuel efficiency. But the major problem is about water absorption properties which further lowers the life and hence percussions are required.

Eberle and Franze [4] estimated the coefficient of reduction in fuel consumption ranges from 0.34 to 0.48 litre/(100 kg *100 km) in case of gasoline powered vehicles while in diesel powered vehicle same will be 0.29 to 0.33 litre/(100 kg*100 km) in European driving cycle. In simple word one $\mathrm{kg}$ reduction in weight can result in saving of 5.94-8.4 litres of gasoline or 5.1-5.8 litres of diesel and corresponding emission due to burning of these fuel over the life time travel of vehicle of 1,75,000 km.

Mechanical properties of natural fiber composite beam and effect of surface treatment are studied by different researchers. Ajith Gopinath et al [5] investigated the mechanical properties of jute fiber composite with polyester and epoxy resin matrices. Jute-epoxy based composite shows better mechanical properties which it them better suited for automotive applications. Ketsara Arrub et al [6] investigated the effect of modification of jute fiber on mechanical properties of green rubber composite beam. The jute fiber surface is modified by soaking in either High Ammonia Natural Rubber (HANR) or De-proteinized Natural Rubber (DPNR). Result shows the improvement in mechanical properties of composite with treatment compared to untreated one. NR/jute treated with DPNR shows improved mechanical properties compared to NR/jute treated HANR. Mechanical properties and effect of alkali treatment and water treatment was studied by Kaushik Sankar et al [7]. N. Rajini et al [8] studied the effect of surface treatment on banana/kenaf reinforcing composite. Use of surface treatment increased the mechanical properties but use of excess amount will damage the fiber surface results in poor mechanical properties.

Effect of layering pattern is carried out by different researchers. C. Deepa et al [9] used combination of hemp, banana and glass fiber to study their characteristics. Five layer laminate is made with top, middle and bottom layer of glass fiber while second and fourth layer are filled by either hemp or glass or combination of hemp/glass fiber. The study favours the use of banana-hemp-glass fiber reinforced hybrid epoxy composite as an alternative of synthesis fiber because of having higher flexural and impact. M. Ramesh et al [10] took similar kind of approach to reduce the glass fiber content by using sisal or jute fiber with combination of glass fiber. Laminate was made up of five layers in which top, middle and bottom layer is made of glass fiber while second and fourth layer are filled by sisal, jute or combination of sisal/jute fiber. Tensile, flexural and impact test are performed and specimens are prepared based on ASTM standard ASTM D368, ASTM D790 and ASTM A370 for respective test. I. Shiva et al [11] investigated the effect of layering pattern on vibrational behaviour of coconut sheath/banana fiber hybrid composite. Banana fiber at core exhibits higher natural frequency than other combinations. There is not much more difference in pure coconut sheath and banana fiber composite, except coconut sheath shows higher flexural strength. 
P. Jayaraj et al [12] studied the effect of Nano clay on hybrid composite beam made up of various combinations and different layering pattern of glass fiber and coconut sheath to improve the performance of coconut sheath fiber with the possible reduction in content of glass fiber generally used. Alkali-treated coconut sheath with Nano clay has maximum tensile and flexural strength among untreated and saline treated coconut sheath with Nano clay and without Nano clay. Alkali treated composite beam having laminate of two lamina namely coconut sheath $(\mathrm{N})$ and glass fiber $(\mathrm{G})$ with the layering pattern of NNG shows optimum increase in mechanical strength and natural frequency which could be used as a replacement of glass fiber. In NNG pattern there is a presence of glass fiber which is considerably low in quantity compare to complete glass fiber composite.

Different researcher studied the free vibration characteristics of natural fiber composite beam. V. Hariharan et al [13] investigated the free vibration characteristics of Phoenix sp fiber reinforced polymer composite beam having different fiber length and weightage fraction of $10 \%$ Experimental results show that composite beam with the $30 \mathrm{~mm}$ fiber length shows highest natural frequency of 32 $\mathrm{Hz}$ while composite beam with $10 \mathrm{~mm}$ and $50 \mathrm{~mm}$ fiber length has natural frequency of $25 \mathrm{~Hz}$ but the amplitude is more for fiber having $50 \mathrm{~mm}$ length.

N. Rajini et al [14] investigated the effect of different weightage fraction on the free vibration characteristics of banana, sisal and hybrid fiber polymer composite beam. Experiment shows that with the increase in fiber percentage mechanical properties like natural frequency and flexural strength also increases. This trend is continue up to $50 \%$ weight fraction, further increment in fiber content in composite decreases the natural frequency and flexural modulus, Because further addition of fiber in composite results in poor adhesion between matrix and fiber which decrease the strength of composite.

Mehmet COLAKOGLU [15] studied the effect of temperature on damping and natural frequency of polyethylene fiber composite beam. There is some functional relationship between damping and temperature, but there is inverse relationship between first natural frequency and temperature as increased in temperature reduce the natural frequency as increase in temperature will decrease the young modulus and there is a relation between natural frequency and young's modulus.

R. S. Lavate et al [16] studied the dynamic response of fiber reinforced composite beam. With the increase in fiber percentage longitudinal tensile strength increases while there is slight increment in transverse tensile and shear strength and longitudinal compressive strength initially increases but then decreases. Free vibration analysis of free-free type composite beam shows the increment in natural frequency with the increment in fiber fraction which is also supported by numerically and analytically.

Khaldoon F. Brethee [17] investigated the effect of cut-out on the free vibration of composite plate, as cutout are commonly used as access ports for connecting mechanical and electrical appliances. Natural frequency increases with the increase in cut-out size as mass reduces.

G. Rajeshkumar et al [18] studied the free vibration analysis of composite beam with different fiber orientation and with different aspect ratio of $(\mathrm{L} / \mathrm{h})$. Composite with $\left(0^{\circ}\right)$ fiber orientation gives maximum natural frequency because of uniform distribution of fiber. There is inverse relationship between natural frequency and aspect ratio as natural frequency decreases with the increase in aspect ratio. Natural frequency of twisting mode is lower than that of deflection mode. With the decrease in aspect ratio twisting mode occurs in lower mode.

Dhanduvari Dinesh Kumar et al [19] presented an experimental approach to study free vibration analysis of woven fiber glass/epoxy laminated composite with different end conditions. The result reveals that the natural frequencies are lower for cantilever beam while clamped-clamped end condition shows higher natural frequency. 


\section{Theoretical Analysis}

\subsection{Young's modulus $\left(E_{c}\right)$}

In case of axial loading,

$$
E_{c}=\left(E_{m} \times V_{m}\right)+\left(E_{f} \times V_{f}\right)
$$

For transverse loading,

$$
\frac{1}{E_{c}}=\frac{V_{f}}{E_{f}}+\frac{V_{m}}{E_{m}}
$$

\subsection{Poison's ratio $\left(\mu_{c}\right)$}

$$
\mu_{c}=\frac{\varepsilon_{t}}{\varepsilon_{l}}=\mu_{f} V_{f}+\mu_{m} V_{m}
$$

\subsection{Density $\left(\rho_{c}\right)$}

$$
\begin{aligned}
& \frac{1}{\rho_{c}}=\frac{W_{f}}{\rho_{f}}+\frac{W_{m}}{\rho_{m}} \\
& \rho_{c}=\rho_{f} V_{f}+\rho_{m} V_{m}
\end{aligned}
$$

\subsection{Natural frequency (f)}

$$
\begin{aligned}
& w=\beta^{2} \sqrt{\frac{E I}{\rho A}}=(\beta l)^{2} \sqrt{\frac{E I}{\rho A l^{4}}} \\
& \mathrm{w}=2 \pi \mathrm{f}
\end{aligned}
$$

Where, $W$ and $V$ are weightage fraction and volume fraction respectively.

\section{Finite Element Modeling}

ANSYS 15.0 is used for analysis purpose. Model analysis module is used for the model analysis.

\begin{tabular}{|l|c|c|c|c|}
\hline \multirow{2}{*}{$\begin{array}{c}\text { Beam } \\
\text { configuration }\end{array}$} & \multirow{2}{*}{ Frequency equation } & \multicolumn{3}{c|}{ Value of $\beta l$ for } \\
\cline { 3 - 5 } & $\begin{array}{c}\mathbf{1}^{\text {st }} \text { natural } \\
\text { frequency }\end{array}$ & $\begin{array}{c}\mathbf{2}^{\text {nd }} \text { natural } \\
\text { frequency }\end{array}$ & $\begin{array}{c}\mathbf{3}^{\text {rd }} \text { natural } \\
\text { frequency }\end{array}$ \\
\hline Clamped-free & $\cosh (\beta l) \cos (\beta l)+1=0$ & 1.875104 & 4.694091 & 7.854757 \\
\hline Clamped-clamped & $\cosh (\beta l) \cos (\beta l)-1=0$ & 4.730041 & 7.853205 & 10.995608 \\
\hline Clamped -supported & $\tan (\beta l)-\tanh (\beta l)=0$ & 3.926602 & 7.068583 & 10.210176 \\
\hline $\begin{array}{l}\text { Supported- } \\
\text { supported }\end{array}$ & $\sin (\beta l)=0$ & $\pi$ & $2 \pi$ & $3 \pi$ \\
\hline
\end{tabular}

Table 1. Governing equation for different beam configuration 


\section{RESUlT AND DiSCUSSION}

Beam of $170 \times 35 \times 3 \mathrm{~mm}^{3}$ is prepared and the properties of fiber and resin are taken from Table 2 and properties of composites and natural frequencies are found out by analytical method and that values are also represented in last row of Table 2. These values are used to find the natural frequencies of composite beam by using analytical method and finite element method using ANSYS. The comparison of natural frequency obtained by finite element method and analytical method is shown in Table 3.

\begin{tabular}{|l|c|c|c|}
\hline \multicolumn{1}{|c|}{ Material } & $\begin{array}{c}\text { Density } \\
\left(\mathbf{k g} / \mathbf{m}^{\mathbf{3}}\right)\end{array}$ & $\begin{array}{c}\text { Young's modulus } \\
\mathbf{( M P a )}\end{array}$ & $\begin{array}{c}\text { Weightage } \\
\text { fraction } \\
(\mathbf{\%})\end{array}$ \\
\hline Banana fiber & 1350 & 3800 & 50 \\
\hline Epoxy resin & 1220 & 3590 & 50 \\
\hline Composite beam & 1282 & 3686 & \\
\hline
\end{tabular}

Table 2. Mechanical properties of banana fiber and epoxy resin

\begin{tabular}{|l|c|c|c|}
\hline \multirow{2}{*}{} & \multicolumn{3}{|c|}{ Natural frequency (Hz) } \\
\cline { 2 - 4 } & Ansys 15.0 & $\begin{array}{c}\text { Analytical } \\
\text { method }\end{array}$ & $\begin{array}{c}\text { M. Rajesh } \text { et. } \text { al. } \\
{[14]}\end{array}$ \\
\hline Mode1 & 28.801 & 28.28 & 28 \\
\hline Mode 2 & 180.05 & 177.65 & 265 \\
\hline Mode 3 & 503.91 & 496 & 550 \\
\hline
\end{tabular}

Table 3.Comparison of natural frequency obtain by different method

\section{Conclusion}

In present study, reviews on mechanical properties of natural fiber composite beam are considered and analytical and finite element analysis is carried out. The natural fiber composite gives moderate mechanical properties and good vibrational characteristics make it available to use the natural fiber composite material for low and moderate load applications.

\section{References}

[1] Furqan Ahmad, Heung Soap Choi and Myung Kyun Park, "A Review: Natural Fiber Composites Selection," Macromolecular Materials and Engineering, p. 2014.

[2] Begum K. and Islam M.A., "Natural Fiber as a substitute to Synthetic Fiber in Polymer Composites:," Research Journal of Engineering Sciences, vol. 2, pp. 46-53, 2013.

[3] S.V. Joshi, L.T. Drzal, A.K. Mohanty and S. Arora, "Are natural fiber composites environmentally superior to glass fiber," Composites Part:A, vol. 35, pp. 371-376, 2004.

[4] Eberle R and Franze H., "Modeling the use phase of passenger cars in LCI.," in SAE Total Lifecycle Conference, Graz Austria, 1998.

[5] Ajith Gopinath, Senthil Kumar.M and Elayaperumal A, "Experimental Investigations on Mechanical Properties," in 12th GLOBAL CONGRESS ON MANUFACTURING AND MANAGEMENT, 2014. 
[6] Pruttipong Pantamanatsopa, Warunee Ariyawiriyanan, Tawatchai Meekeaw, Rattiyakorn Suthamyong, Ketsara Arrub and Hiroyuki Hamada, "Effect of Modified Jute Fiber on Mechanical Properties of Green Rubber Composite," Energy Procedia, vol. 56, pp. 641-647, 2014.

[7] Ruy A. Sa Ribeiro, Marilene G. Sa Ribeiro, Kaushik Sankar and Waltraud M. Kriven, "Geopolymer-Bamboo Composite - A Novel Sustainable Construction Material," Construction and Building Materials, vol. 123, pp. 501-507, 2016.

[8] A. Alavudeen, N. Rajini, S. Karthikeyan, M. Thiruchitrambalam and N. Venkateshwaren, "Mechanical Properties of Banana/kenaf Fiber Composite-reinforced Hybrid Polyester Composite: Effect of Woven Fabric and Random Orientation," Materials and Design, 2014.

[9] R. Bhoopathi, M. Ramesh and C. Deepa, "Fabrication and Property Evaluation of Banana-HempGlass Fiber Reinforced Composites," in 12th GLOBAL CONGRESS ON MANUFACTURING AND MANAGEMENT, 2014.

[10] M. Ramesh, K. Palanikumar and K. Hemachandra Reddy, "reinforced, Mechanical property evaluation of sisal-jute-glass fiber," Composite: Part B, vol. 48, pp. 1-9, 2013.

[11] K. Senthil Kumar, I. Shiva, N. Rajini, J. T. Winowlin Jappes and S. C. Amico, "Layering Pattern Effect on Vibrational Behavior of Coconut Sheath/Banana Fiber Hybrid composite," Materials and design, vol. 90, pp. 795-803, 2016.

[12] N Rajini, JT Winowlin Jappes, S Rajakarunakaran and P. Jeyaraj, "Mechanical and free vibration properties of montmorillonite clay dispersed with naturally woven coconut sheath composite," Journal of Reinforced Plastics and Composites, vol. 31, pp. 1364-1376, 2012.

[13] G.Rajeshkumar and V.Hariharan, "Free Vibration Characteristics of Phoenix Sp Fiber Reinforced," in 12th GLOBAL CONGRESS ON MANUFACTURING AND MANAGEMENT, 2014.

[14] M Rajesh, Jeyaraj Pitchaimani and N Rajini, "Free Vibration Characteristics of Banana/Sisal Natural Fibers Reinforced Hybrid Polymer Composite Beam," in 12th International Conference on Vibration Problems, 2015.

[15] Mehmet COLAKOGLU, "Damping And Vibration Analysis of Polyethylene Fiber Composite under Varied Temperature," Turkish journal of Engineering and Environmental Science, vol. 30, pp. 351-357, 2006.

[16] R. S. Lavate, A. T. Patil, A. M. Patil and N. V. Hargude, "Dynamic Response Analysis of Fiber Reinforced Composite Beam," in Second International Conference in Emerging Trend in Engineering.

[17] Khaldoon Brethee, "Free Vibration Analysis of a Symmetric and Anti-Symmetric Laminated Composite Plate with a Cutout at The Center," Al-Qadisiya Journal for Engineering Sciences, vol. 2, 2009.

[18] G. RajeshKumar and V. Hariharan, "Free Vibration Analysis of Hybrid-Composite Beams," in International Conference on Advantages In Engineering, Science and Mangement, 2012.

[19] Dhandurvi Dinesh Kumar, Gundala Shivaprasad, Sri Hari M and Vinay Kumar Reddy V, "An Experimental and Numerical Approach to Free Vibration Analysis of Glass/Epoxy Laminated Composite Plates," International Journal of Engineering Research and Technology, vol. 4, pp. 559-563, 2015. 